\title{
The long-term incidence and predictors of radial artery occlusion following a transradial coronary procedure
}

\author{
Ali Buturak ${ }^{1}$, Sevket Gorgulu ${ }^{1}$, Tugrul Norgaz ${ }^{1}$, Nuray Voyvoda $^{2}$, \\ Yusuf Sahingoz ${ }^{2}$, Aleks Degirmencioglu ${ }^{1}$, Sinan Dagdelen ${ }^{1}$ \\ ${ }^{1}$ Cardiology Department, Acıbadem University School of Medicine, Istanbul, Turkey \\ ${ }^{2}$ Radiology Department, Acıbadem Kocaeli Hospital, Istanbul, Turkey
}

\begin{abstract}
Background: Radial artery occlusion (RAO) is an infrequent complication of transradial coronary procedures (TRA). To our knowledge, there is no satisfactory data regarding the late term incidence and predictors of RAO in the literature. Our aim was to establish the long-term incidence of radial artery occlusion and investigate its predictors.

Methods: This was a single center prospective study. A total number of 409 consecutive patients undergoing their first TRA were recruited. Clinical and procedural data were all recorded. Doppler ultrasound examination was performed at 6-15 months following the intervention.

Results: RAO was detected in 67 patients and 342 patients maintained radial artery patency. The overall RAO incidence was $16.4 \%$ at late term. Patients with RAO were younger than the patients with patent radial arteries (55.9 $\pm 9.7 v$ s. $59.1 \pm 9.4$ years, $p=0.014)$. The incidence of RAO in hypertensive patients $(9.8 \%)$ was lower $(p<0.001)$ than the observed incidence (23\%) in non-hypertensive patients. RAO group had higher rate $(28 \%, p=0.027)$ of post-procedural access site pain. Regression analysis revealed that hypertension was negative while post-procedural access site pain was positive independent predictors for RAO. In addition, the relative risk for $R A O$ also increased significantly $(p<0.001)$ when the ratio of sheath/artery diameter $(S / A)$ was $>1$.

Conclusions: The present study reveals that the long-term incidence of $R A O$ is $16.4 \%$. Hypertension, post-procedural access site pain and $S / A$ ratio $>1$ are independent predictors of RAO at late term. (Cardiol J 2014; 21, 4: 350-356)
\end{abstract}

Key words: radial artery occlusion, predictors

\section{Introduction}

Radial artery occlusion (RAO) is a complication of transradial coronary procedures (TRA) which can lead to permanent occlusion of the radial artery.
This complication is not benign, as hand ischemia, resulting from RAO, has been reported $[1,2]$. Furthermore, once the artery is occluded, it cannot be used as an access site for future catheterizations or as an arterial conduit for bypass surgery.

Address for correspondence: Ali Buturak, MD, Acıbadem Kadıköy Hastanesi, Tekin S, No:8 Kadıköy, Istanbul, Turkey, tel: +902164580808, fax: +902165898485, e-mail: alibuturak@yahoo.com

Received: 18.07.2013 Accepted: 07.08.2013 
In the literature, the reported RAO incidence of patients undergoing TRA varies from $1 \%$ to $10 \%$ [3-5]. In all these studies, RAO was evaluated in the early period (up to 1 month) follow-up. However, spontaneous recanalization of the radial artery was as long as 3 months after decannulation [6]. The underlying mechanism of occlusion in the early period is the presence of radial artery thrombus. Data on the long-term course of patients with RAO are limited. In a study conducted by Nagai et al. [5], the total incidence of RAO at the end of 3-month follow-up was $5 \%$. Chronic phase vascular complications such as diffuse stenosis and loss of forward flow occur at a period of 1 to 6 months following the procedure [5]. However, there is no report regarding the incidence of RAO after a follow-up period of 6 months following TRA. Therefore, our aim was to investigate the long-term incidence of $\mathrm{RAO}$ and to find out its predictors.

\section{Methods}

\section{Patient population}

This was a single center prospective study. After applying the exclusion criteria, a total number of 409 consecutive patients undergoing their first transradial coronary angiography were recruited from May to October 2010. Patients with previous transradial procedure $(\mathrm{n}=15)$ and abnormal Allen test $(n=10)$ were excluded. Procedures were performed by 2 experienced high-volume radial operators (with a personal experience of $>1000$ cases). All of these patients gave written informed consent and the study was approved by the ethics committee of Acrbadem University School of Medicine.

\section{Radial artery cannulation, retrograde radial arteriography and subclavian arteriography}

After local subcutaneous anesthesia with $1 \%$ lidocaine, radial artery puncture was performed with a dedicated radial cannulation needle and guide wire. A hydrophilic $5 \mathrm{~F}$ or $6 \mathrm{~F}$ sheath (Terumo, Japan) was used to complete arterial puncture, then $500 \mu \mathrm{g}$ glycerol trinitrate and $2.5 \mathrm{mg}$ verapamil were injected into radial artery along the sheath. Heparin 5,000 IU was given in the aortic root. Retrograde radial arteriography was performed as previously described [7]. If the operator encountered serious problems, which meant the need for a hydrophilic guide wire, or difficulty in engaging the coronary ostia with an exaggerated S-shape configuration of the catheter or wire, during crossing the subclavian-aortic truncus, retrograde subclavian arteriography was also performed.

\section{Transradial coronary procedure}

For coronary angiography and intervention, the catheters to be employed were $5 \mathrm{~F}$ or $6 \mathrm{~F}$ size catheters. If the patient needed revascularization after angiography, the procedure was completed with an ad hoc percutaneous coronary intervention. In these patients, an additional bolus of 5,000 IU heparin was administered. Once the introducer was withdrawn immediately after the procedure, hemostasis was achieved by means of manual compression and pressure dressing, which was performed by a registered and trained nurse. Patients were allowed to walk around immediately after the end of the procedure. All the patients were discharged on the third hour after TRA.

\section{Classification and definitions}

Anomalies of the upper limb arteries were recorded and defined as previously described [7]. Brachial and subclavian artery tortuosity was defined as angulation of the artery more than $90^{\circ}$.

Procedure success was defined as coronary angiography completed with the initial radial artery approach without changing to another route.

Sheath removal time (minutes) was defined as the time interval between the insertion of the sheath and its removal.

Any stenosis in the radial artery greater than $25 \%$ at the distal of the puncture needle or sheath was defined as radial artery spasm (RAS) [8]. RAS was diagnosed by at least 2 experienced operators. After radial arteriography, off-line quantitative analysis was used to determine the percentage of stenosis.

Post-procedural pain was characterized as access site or forearm pain following compression and hemostasis with or without swelling in any time between in-hospital and out-hospital follow-up.

Major vascular complications were defined as vascular access complications which required surgical or radiological intervention, hematoma $>5 \mathrm{~cm}$, red cell transfusion at the discretion of the treating physician or which led to a drop in hemoglobin level of more than $3 \mathrm{~g} / \mathrm{dL}$, limb ischemia and/or compartment syndrome.

Minor vascular complications were defined as vessel dissection and rupture without leading to ischemia, hematoma less than $5 \mathrm{~cm}$, pseudo-aneurysm, arteriovenous fistulae and localized infection. 


\section{Doppler ultrasound measurements}

RAO was assessed by ultrasound examination at least 6 months (average $11.3 \pm 1.5$ month) after the procedure. All sonographic examinations were performed by 2 experienced radiologists, who had no knowledge of the catheterization procedure, using a Siemens (Acuson, Antares Premium edition US System, Siemens, Munich, Germany) ultrasound machine with a multifrequency linear probe. Subject's right and left forearms were in supination with a pillow placed under wrists. The probe was placed on the ventral wrist to parallel the long axis of the forearm, using the color mode to localize the radial artery. The measurements were collected at the segment $5 \mathrm{~mm}$ distal to the radial styloid process. The luminal diameter of the radial artery was assessed by superimposing 2-dimensional sonography to the comparative image of the color Doppler. The radial flow was assessed by Doppler measurement, and flow was graded from 0 to 3 as previously described [9]. RAO was defined as the presence of grade $0-1$ flow on Doppler examination.

Ratio of sheath size to radial artery diameter (S/A) was estimated by dividing the value of the observed radial artery luminal diameter (in milimeters) to 1.65 for $5 \mathrm{~F}$ sheaths and to 1.98 for $6 \mathrm{~F}$ sheaths.

\section{Data collection}

Demographic and clinical characteristics of the patients were recorded. Total procedure and fluoroscopy time (in minutes), amount of contrast used (in milliliters), sheath size ( $5 \mathrm{~F}$ or $6 \mathrm{~F}$ ), sheath removal time (in minutes), access site (right or left radial artery), heparin dose (5,000 or 10,000 IU), peri-procedural RAS, peri-procedural radial artery rupture, and presence of post-procedural access site pain were also recorded. Radial artery Doppler findings as radial artery diameter and flow were also registered.

\section{Statistical analysis}

All analyses were performed using SigmaPlot 11.0 statistical software (Systat Software Inc., San Jose, California). Continuous data were summarized as mean \pm standard deviation. Categorical variables were expressed as absolute values and percentages. Multiple logistic linear regression analysis was performed to identify independent predictors of RAO. Continuous variables were compared using Student's t test and Mann-Whitney U test, as appropriate. Differences between categorical variables were examined using the $\chi^{2}$ test. P values of $<0.05$ were considered statistically significant.
Table 1. Demographics and clinical characteristics of the study population.

\begin{tabular}{lc}
\hline Age [year] & $58.5 \pm 9.4$ \\
Body weight $[\mathrm{kg}]$ & $81.4 \pm 14.3$ \\
Height $[\mathrm{cm}]$ & $168 \pm 8$ \\
Body mass index $\left[\mathrm{kg} / \mathrm{m}^{2}\right]$ & $28.9 \pm 5.0$ \\
Male & $276(67.5 \%)$ \\
Female & $133(32.5 \%)$ \\
Risk factors: & \\
$\quad$ Hypertension & $203(49.6 \%)$ \\
$\quad$ Diabetes & $103(25.2 \%)$ \\
$\quad$ Smoking & $131(32.0 \%)$ \\
Clinical presentations & \\
$\quad$ Stabile angina & $289(70.7 \%)$ \\
$\quad$ ACS & $110(26.9 \%)$ \\
$\quad$ History of CABG & $12(2.4 \%)$ \\
DUT [months] & $11.3 \pm 1.5$ \\
Radial artery occlusion & $67(16.4 \%)$ \\
\hline
\end{tabular}

ACS - acute coronary syndrome; CABG — coronary artery bypass grafting; DUT — Doppler ultrasonography time

\section{Results}

\section{Demographic and clinical characteristics of study population}

Study population consisted of 409 patients with mean age $58.5 \pm 9.4$ years, $67 \%$ male. Doppler ultrasonography was performed to study patients at 6 to 15 months after a TRA. The mean follow up period was $11.3 \pm 1.5$ months prospectively. The RAO was observed in 67 patients $(16.4 \%$ of the study population). Table 1 summarizes demographic and clinical characteristics of the study population.

\section{Demographic and clinical characteristics of study groups}

The patients were divided into two groups according to the patency of radial artery estimated by late Doppler ultrasound examination; patent radial artery (RAP group) and occluded radial artery group (RAO group). Table 2 summarizes demographic and clinical characteristics of these two groups of patients. Prevalence of diabetes mellitus in both groups was similar (Table 2), while the prevalence of hypertension was significantly lower in the RAO group (hypertension rates; RAP 54\% vs. RAO $30 \%, \mathrm{p}<0.001)$.

\section{Procedural and Doppler data in RAP and RAO groups}

Table 3 summarizes the procedural and Doppler data for RAP and RAO groups. The pro- 
Table 2. Demographic and clinical characteristics of the study groups.

\begin{tabular}{|c|c|c|c|}
\hline & \multicolumn{2}{|c|}{ Study groups } & \multirow[t]{2}{*}{$\mathbf{P}$} \\
\hline & RAP (n = 342) & RAO (n = 67) & \\
\hline Age [year] & $59.1 \pm 9.4$ & $55.9 \pm 9.7$ & $0.014^{*}$ \\
\hline Male gender & $233(68 \%)$ & $43(64 \%)$ & NS \\
\hline Height $[\mathrm{cm}]$ & $168.1 \pm 7.4$ & $166.9 \pm 8.2$ & NS \\
\hline Weight [kg] & $81.5 \pm 14.3$ & $80.6 \pm 14.7$ & NS \\
\hline Body mass index $\left[\mathrm{kg} / \mathrm{m}^{2}\right]$ & $28.9 \pm 4.9$ & $28.9 \pm 5.5$ & NS \\
\hline Diabetes mellitus & $89(26 \%)$ & $14(21 \%)$ & NS \\
\hline Hypertension & $183(54 \%)$ & $20(30 \%)$ & $<0.001^{*}$ \\
\hline Smoking & $104(30 \%)$ & $27(40 \%)$ & NS \\
\hline History of CABG & $11(3 \%)$ & $1(1 \%)$ & NS \\
\hline Stable angina & $245(71 \%)$ & $44(65 \%)$ & NS \\
\hline Acute coronary syndrome & $90(26 \%)$ & $20(29 \%)$ & NS \\
\hline Fasting glucose [mg/dL] & $129.8 \pm 60.9$ & $125.4 \pm 59.1$ & NS \\
\hline Creatinine $[\mathrm{mg} / \mathrm{dL}]$ & $0.85 \pm 0.22$ & $0.85 \pm 0.20$ & NS \\
\hline Total cholesterol [mg/dL] & $197.6 \pm 49.1$ & $185.7 \pm 62.7$ & NS \\
\hline Triglycerides [mg/dL] & $161.84 \pm 68.2$ & $144.25 \pm 64.3$ & NS \\
\hline Aspirin & $172(50 \%)$ & $33(49 \%)$ & NS \\
\hline Clopidogrel & $7(2 \%)$ & $1(1 \%)$ & NS \\
\hline Aspirin + clopidogrel & $41(12 \%)$ & $11(16 \%)$ & NS \\
\hline Warfarin & $12(3 \%)$ & $2(2 \%)$ & NS \\
\hline
\end{tabular}

${ }^{*}$ Statistically significant value; CABG — coronary artery bypass grefting; NS — non-significant; RAP — patent radial artery; RAO — radial artery occlusion

Table 3. Procedural and Doppler data of the patients.

\begin{tabular}{|c|c|c|c|}
\hline & \multicolumn{2}{|c|}{ Study groups } & \multirow[t]{2}{*}{$\mathbf{P}$} \\
\hline & $\operatorname{RAP}(n=342)$ & RAO (n = 67) & \\
\hline Procedure time [min] & $7.8 \pm 3.6$ & $8.4 \pm 3.8$ & 0.260 \\
\hline Fluoroscopy time [min] & $2.8 \pm 2.1$ & $2.97 \pm 1.8$ & 0.471 \\
\hline Amount of contrast [mL] & $58.9 \pm 20.5$ & $57.1 \pm 17.3$ & 0.482 \\
\hline Dose area product $\left[\mathrm{Gy}^{*} \mathrm{~cm}^{2}\right]$ & $2153 \pm 1372$ & $1883 \pm 929$ & 0.126 \\
\hline \multicolumn{4}{|l|}{ Sheath size: } \\
\hline 5 French sheath & $152(45 \%)$ & $31(46 \%)$ & 0.920 \\
\hline 6 French sheath & $190(55 \%)$ & $36(54 \%)$ & \\
\hline Number of catheters used & $2.0 \pm 0.26$ & $2.0 \pm 0.21$ & 0.644 \\
\hline Number of guidewires used & $1.17 \pm 0.44$ & $1.18 \pm 0.42$ & 0.713 \\
\hline Sheath removal time [min] & $32.30 \pm 17.1$ & $30.33 \pm 13.0$ & 0.952 \\
\hline Right radial access & $192(56 \%)$ & $35(52 \%)$ & 0.650 \\
\hline Number of $\mathrm{PCl}$ & $77(22 \%)$ & $10(15 \%)$ & 0.221 \\
\hline \multicolumn{4}{|l|}{ Heparin dose: } \\
\hline $5,000 \mathrm{IU}$ & $322(94 \%)$ & $63(94 \%)$ & 0.806 \\
\hline $10,000 \mathrm{IU}$ & $18(5 \%)$ & $4(5 \%)$ & 0.943 \\
\hline Radial artery spasm & $24(7 \%)$ & $8(12 \%)$ & 0.261 \\
\hline Rupture & $2(0.5 \%)$ & $0(0 \%)$ & 0.741 \\
\hline Post-procedural pain & $55(16 \%)$ & $19(28 \%)$ & $0.027^{*}$ \\
\hline Total vascular anomalies ${ }^{\#}$ & $77(22 \%)$ & $11(16 \%)$ & 0.664 \\
\hline Radial artery diameter [mm] & $2.30 \pm 0.40$ & $1.80 \pm 0.51$ & $<0.001^{*}$ \\
\hline $\mathrm{S} / \mathrm{A}$ ratio & $0.84 \pm 0.19$ & $1.12 \pm 0.38$ & $<0.001^{*}$ \\
\hline $\mathrm{S} / \mathrm{A}$ ratio $>1$ & $45(13 \%)$ & $46(69 \%)$ & $<0.001^{*}$ \\
\hline
\end{tabular}

*Statistically significant; "includes radial loop, high bifurcation, tortuosity of radial, brachial and axillary arteries and remnant radial artery.

High radial bifurcation ( $\mathrm{n}=39,9 \%)$ and subclavian tortuosity $(\mathrm{n}=28,7 \%)$ were the two most common vascular anomalies; IU - International unit; $\mathrm{PCl}$ - percutaneous coronary intervention; RAP — patent radial artery; RAO — radial artery occlusion; S/A ratio - ratio of sheath size to estimated radial artery diameter 
cedure time, fluoroscopy time, used amount of contrast, dose area product, number of catheters and guide wires used were similar in both groups (Table 3). There was no difference regarding the use of $5 \mathrm{~F}$ and $6 \mathrm{~F}$ sheaths and sheath removal times between the groups. Heparin doses (5,000 or $10,000 \mathrm{IU}$ ) and number of percutaneous coronary intervention performed were also not significantly different between the two groups (Table 3).

Doppler ultrasound examination revealed that the radial artery diameter in the RAO group was $(1.8 \pm 0.5 \mathrm{~mm})$ significantly $(\mathrm{p}<0.001)$ narrower than the observed value $(2.3 \pm 0.4 \mathrm{~mm})$ for the RAP group. The radial artery diameter was positively correlated with body weight $(\mathrm{r}=0.254$, $\mathrm{p}<0.001)$, height $(\mathrm{r}=0.211, \mathrm{p}<0.001)$ and body mass index $(r=0.144, p<0.01)$.

\section{Predictors of RAO}

The RAO group was younger than the RAP group (Table 2). The incidence of RAO was lower in hypertensive patients (RAP group $54 \%$ vs. RAO group $30 \%, \mathrm{p}<0.001$ ) and higher in patients with post-procedural access site pain (RAP group 16\% vs. RAO group $28 \%, \mathrm{p}=0.027)$. $\mathrm{S} / \mathrm{A}$ ratio in $\mathrm{RAO}$ group was $(1.12 \pm 0.38)$ significantly $(\mathrm{p}<0.001)$ higher than the observed value $(0.84 \pm 0.19)$ for the RAP group. In addition, the rate of patients with $\mathrm{S} / \mathrm{A}$ ratio $>1$ in the RAO group was $69 \%$, significantly $(\mathrm{p}<0.001)$ higher than the estimated value (13\%) for the RAP group.

Multiple logistic regression analysis revealed that presence of hypertension was an independent strong negative predictor $(\mathrm{p}<0.001)$ of RAO. The relative risk for RAO decreased to 0.432 (95\% CI 0.266-0.702) in the presence of hypertension. Likewise, multiple logistic regression analysis revealed that post-procedural access site pain was also a significant $(\mathrm{p}=0.027)$ predictor for RAO. The relative risk for RAO in presence of the post-procedural access site pain increased to 1.792 (95\% CI 1.122-2.861). When S/A ratio were $>1$, the relative risk for RAO increased significantly to 5.764 (95\% CI 3.390-9.800).

\section{Discussion}

The present study established a higher incidence of RAO (16.4\%) compared with previously declared literature [3-5]. This discrepancy is understandable from our point of view as our study differs in two ways from other reports.

Firstly, to our knowledge this study is the first in terms of investigating the RAO incidence in the long-term with an average of $11.2 \pm 1.5$ months follow up after the procedure. In other words, the concerned incidence of RAO seems to represent the complication rates of both acute and chronic injuries. As the present study did not provide serial observations of the radial artery used for TRA, it is troublesome to define precisely which mechanism was mostly involved in our $16 \%$ RAO rate. Recently, Yonetsu et al. [10] demonstrated a smaller lumen diameter and increased intimal thickening of the radial artery at a mean period of 11 months after the first trans-radial procedure in patients who have underwent repeated TRA. In a study by Nagai et al. [5], the incidence of RAO was found to be $5 \%$ by evaluation of the radial artery at $95 \pm 29$ days following the procedure. This short period of follow up equals with the ongoing process of both remodeling and intimal thickening [11, 12]. Likewise, chronic phase vascular complications such as diffuse stenosis and loss of forward flow may mimic the same physiopathology of restenosis related to angioplasty $[13,14]$. Therefore, one might argue whether it is reasonable to expect a higher incidence of RAO at a longer follow-up (at least 6 months).

Secondly, RAO was diagnosed in all patients by ultrasonographic examination in contrast to previous studies in which diagnosis was made by absence of pulse [3, 15-17]. False positive pulses may result in underestimation of the incidence of RAO [5]. Thus, the diagnosis of RAO should be confirmed using a more objective technique such as duplex ultrasonography, which was lacking or was not included in all patients in most of the studies [18].

Several studies examining the rates of RAO have used multivariable models to identify independent predictors of RAO. The following factors have been identified as independent predictors in the majority of studies: the diameter of the sheath and its relationship to the size of the radial artery, post-procedure compression time and the presence of antegrade flow in the artery during hemostasis, and the use of anticoagulation [4, 5, 19-21]. Except the sheath-to artery ratio, none of the remaining predictors determined the development of RAO in our study. The physiopathology of early RAO is related to thrombus formation [22] and the above mentioned predictors make sense in the early period of RAO. However, the predictors of $\mathrm{RAO}$ in the long-term period were found to be the sheath-to artery ratio $>1(\mathrm{p}<0.001)$, absence of hypertension $(\mathrm{p}<0.001)$ and post-procedural pain $(\mathrm{p}=0.027)$ in our study. 
Severe flow reduction was found in patients with a sheath-to-artery ratio ( $\mathrm{S} / \mathrm{A}$ ratio) $>1$ [9]. Others have made similar observations $[5,20]$. Likewise, the concerned ratio was an independent predictor of long-term RAO in our study $(\mathrm{p}<0.001)$. As we know, the inner luminal diameter of the radial artery decreases after TRA at late term [23], the rational cause responsible for this undesirable complication might be the extensive structural damage caused by sheath insertion which in turn triggers for the events of intimal hyperplasia and vascular remodeling $[11,24]$.

Gwon et al. [25] indicated that an S/A ratio $>1$ is associated with pain during sheath insertion and removal. Post-procedural pain, which was found as an independent predictor of radial artery patency in our study, may be a clue of extensive structural damage triggering the cascade of events resulting in hyperplasia, remodeling, and finally occlusion.

The mechanism of hypertension being a predictor of the long-term patency of the radial artery remains elusive. We speculate that hypertension produces a steeper increase in radial artery flow, hence, reopening the occlusion in the early period and maintain vessel patency in the long-term consequently. Another speculation might be that the arterial stiffness in hypertension may preclude the total interruption of flow during manual compression, thus providing adequate maintenance of perfusion. In other words, patent hemostasis, which has been shown to decrease the rate of RAO [26, 27], might be the mechanism in our hypertensive patients.

\section{Limitations of the study}

The present study has several limitations. Hemostasis of radial artery access site was achieved by manual compression and pressure dressing which may affect patent hemostasis. Another issue is that Doppler ultrasound imagination was not performed just before discharge to evaluate acute occlusion but this could be the subject of a further study to compare early and late term radiologic findings of the vessel following TRA.

\section{Conclusions}

The present study reveals that the long-term incidence of $\mathrm{RAO}$ is $16.4 \%$. S/A ratio $>1$, hypertension and post-procedural access site pain are independent predictors of RAO at late term.

\section{Acknowledgements}

We would like to thank Prof. İsmail Hakkı Ulus for his great contribution to data analysis and interpretation of the results of the present study.

\section{References}

1. Ryne D, Mann T. Hand ischemia resulting from a transradial intervention: Successful management with radial angioplasty. Catheter Cardiovasc Interv, 2010; 76: 383-386.

2. Ruzsa Z, Pinter L, Kolvenbach R. Antegrad recanalisation of the radial artery followed by transradial angioplasty. Cardiovasc Revasc Med, 2010; 11: 266: e261-e264.

3. Stella PR, Kiemeneij F, Laarman GJ, Odekerken D, Slagboom T, van der Wieken R. Incidence and outcome of radial artery occlusion following transradial artery coronary angioplasty. Catheter Cardiovasc Diagnosis, 1997; 40: 156-158.

4. Sanmartin M, Gomez M, Rumoroso JR et al. Interruption of blood flow during compression and radial artery occlusion after transradial catheterization. Catheter Cardiovasc Interv, 2007; 70: 185-189.

5. Nagai S, Abe S, Sato T, Hozawa K et al. Ultrasonic assessment of vascular complications in coronary angiography and angioplasty after transradial approach. Am J Cardiol, 1999; 83: 180-186.

6. Bedford RF, Wollman H. Complications of percutaneous radial artery cannulation: An objective prospective study in man. Anesthesiology, 1973; 38: 228-236.

7. Lo TS, Nolan J, Fountzopoulos E et al. Radial artery anomaly and its influence on transradial coronary procedural outcome. Heart, 2009; 95: 410-415.

8. Gorgulu S, Norgaz T, Karaahmet T, Dagdelen S. Incidence and predictors of radial artery spasm at the beginning of a transradial coronary procedure. J Interv Cardiol, 2013; 26: 208-213.

9. Saito S, Ikei H, Hosokawa G, Tanaka S. Influence of the ratio between radial artery inner diameter and sheath outer diameter on radial artery flow after transradial coronary intervention. Catheter Cardiovasc Interv, 1999; 46: 173-178.

10. Yonetsu T, Kakuta T, Lee T et al. Assessment of acute injuries and chronic intimal thickening of the radial artery after transradial coronary intervention by optical coherence tomography. Eur Heart J, 2010; 31: 1608-1615.

11. Mintz GS, Popma JJ, Pichard AD et al. Arterial remodeling after coronary angioplasty: A serial intravascular ultrasound study. Circulation, 1996; 94: 35-43.

12. Kimura T, Kaburagi S, Tamura T et al. Remodeling of human coronary arteries undergoing coronary angioplasty or atherectomy. Circulation, 1997; 96: 475-483.

13. Serruys PW, Luijten HE, Beatt KJ et al. Incidence of restenosis after successful coronary angioplasty: A time-related phenomenon. A quantitative angiographic study in 342 consecutive patients at 1, 2, 3, and 4 months. Circulation, 1988; 77: 361-371.

14. Nobuyoshi M, Kimura T, Nosaka H et al. Restenosis after successful percutaneous transluminal coronary angioplasty: Serial angiographic follow-up of 229 patients. J Am Coll Cardiol, 1988; 12: $616-623$.

15. Kiemeneij F, Laarman GJ, Odekerken D, Slagboom T, van der Wieken R. A randomized comparison of percutaneous transluminal coronary angioplasty by the radial, brachial and femoral approaches: The access study. J Am Coll Cardiol, 1997; 29: 1269-1275.

16. Kiemeneij F, Laarman GJ, Slagboom T, Van der Wieken R. Outpatient coronary stent implantation. J Am Coll Cardiol, 1997; 29: 323-327.

17. Lotan C, Hasin Y, Mosseri M et al. Transradial approach for coronary angiography and angioplasty. Am J Cardiol, 1995; 76: 164-167.

Conflict of interest: none declared 
18. Kotowycz MA, Dzavik V. Radial artery patency after tranradial catheterization. Circ Cardiovasc Interv, 2012; 5: 127-133.

19. Zhou YJ, Zhao YX, Cao Z et al. Incidence and risk factors of acute radial artery occlusion following transradial percutaneous coronary intervention. Zhonghua Yi Xue Za Zhi, 2007; 87: 1531-1534.

20. Yoo BS, Yoon J, Ko JY et al. Anatomical consideration of the radial artery for transradial coronary procedures: Arterial diameter, branching anomaly and vessel tortuosity. Int J Cardiol, 2005; 101: 421-427.

21. Pancholy SB. Impact of two different hemostatic devices on radial artery outcomes after transradial catheterization. J Invasive Cardiol, 2009; 21: 101-104.

22. Pancholy SB. Transradial access in an occluded radial artery: New technique. J Invasive Cardiol, 2007; 19: 541-544.

23. Yoo BS, Lee SH, Ko JY et al. Procedural outcomes of repeated transradial coronary procedure. Catheter Cardiovasc Interv, 2003; 58: 301-304.
24. Pratt RE, Dzau VJ. Pharmacological strategies to prevent restenosis: Lessons learned from blockade of the renin-angiotensin system. Circulation, 1996; 93: 848-852.

25. Gwon HC, Doh JH, Choi JH et al. A 5Fr catheter approach reduces patient discomfort during transradial coronary intervention compared with a 6 Fr approach: A prospective randomized study. J Interv Cardiol, 2006; 19: 141-147.

26. Cubero JM, Lombardo J, Pedrosa C et al. Radial compression guided by mean artery pressure versus standard compression with a pneumatic device (RACOMAP). Catheter Cardiovasc Interv, 2009; 73: 467-472.

27. Pancholy S, Coppola J, Patel T, Roke-Thomas M. Prevention of radial artery occlusion-patent hemostasis evaluation trial (PROPHET study): A randomized comparison of traditional versus patency documented hemostasis after transradial catheterization. Catheter Cardiovasc Interv, 2008; 72: 335-340. 